Check for updates

Cite this: RSC Adv., 2020, 10, 23080

Received 9th March 2020

Accepted 1st June 2020

DOI: 10.1039/d0ra02195d

rsc.li/rsc-advances

\section{Terpyridine-based Pd(II)/Ni(II) organometallic framework nano-sheets supported on graphene oxide-investigating the fabrication, tuning of catalytic properties and synergetic effects $\uparrow$}

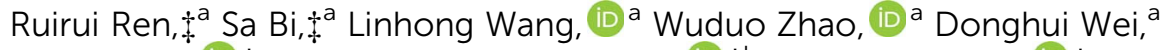
Tiesheng Li, (D) *a Wenjian Xu, ${ }^{a}$ Minghua Liu (D) *bc and Yangjie Wu (DD *a

Tailoring the structures of catalysts and the arrangement of organic bimetallic catalysts are essential in both fundamental research and applications. However, they still impose enormous challenges such as size and active species distribution, ordered uniformity, and controllable composition, which are critical in determining their specific activities and efficiency. Herein, a novel terpyridine-based hetero-bimetallic $\mathrm{Ni} / \mathrm{Pd}$ nanosheet supported on graphene oxide (denoted as GOaTpy-Ni/Pd) was fabricated, which exhibited higher catalytic activity, substrate applicability and recyclability for the Suzuki coupling reaction under mild conditions. The catalytic mechanism was heterogeneous catalysis at the interface and the synergetic effect between $\mathrm{Pd}$ and $\mathrm{Ni}$ resulted in a little $\mathrm{Ni}(0) / \mathrm{Pd}(0)$ cluster including $\mathrm{Pd}(॥) / \mathrm{Ni}(॥)$ as a whole being formed through electron transfer on the catalytic surface. This phenomenon could be interpreted as the nanoscale clusters of $\mathrm{Ni} / \mathrm{Pd}$ being the real active centre stabilized by the ligand and $\mathrm{GO}$ and the synergetic effect. The absorption and desorption of different substrates and products on Ni/Pd clusters, as calculated by DFT, was proved to be another key factor.
\end{abstract}

\section{Introduction}

Transition-metal-catalyzed cross-couplings have become truly fundamental tools for organic synthesis. ${ }^{1-3}$ Hetero-multimetallic catalysts show new performances and capabilities due to the synergistic effects between the metals..$^{4-6}$ In the last few decades, many hetero-bimetallic nanostructures, including nickel-based, nanoparticles, were widely used in industrial processes owing to their conspicuous activity and outstanding recyclability. ${ }^{7-15}$ These nanoparticles, with high catalytic activity, were also the most disposed to aggregation, which affected their catalytic performance. ${ }^{16}$ To solve this problem, appropriate supports and ligands, such as carbon materials and other materials, could strongly prevent metal species from aggregating. ${ }^{17}$ Nevertheless, practical supported hetero-multimetallic nanocatalysts did not have well-distributed states that could reduce the catalytic efficiency and the emergence of undesired side reactions. ${ }^{16}$ It also made it extremely difficult to

${ }^{a}$ College of Chemistry, Zhengzhou University, Zhengzhou, 450001, P. R. China

${ }^{b}$ Henan Institute of Advanced Technology, Zhengzhou University, Zhengzhou 450001, P. R. China

${ }^{C}$ Beijing National Laboratory for Molecular Science, Institute of Chemistry, Chinese Academy of Sciences, Zhongguancun North First Street 2, Beijing 100190, P. R. China $\dagger$ Electronic supplementary information (ESI) available. See DOI: $10.1039 /$ d0ra02195d

$\ddagger$ Contributed equally to this work. control the ratio and electron distribution, which were essential for enhancing catalytic activity. ${ }^{18}$ Therefore, understanding the fundamental mechanisms involved in how to form uniform active centres, why each component interacted and what was the optimized combination for deeply affecting the overall properties became more important research. ${ }^{19,20}$ It was also very important for the metal catalysts to be supported, since nanoparticles of catalysts only having very weak interaction with supports might easily aggregate and leach, resulting in degrading performance. Covalent attachment was a very effective method for anchoring catalytic active centres. ${ }^{21,22}$ Therefore, the rational fabrication of the ordered self-assembled (SAM) catalytic monolayer and its functionality during catalysis must be investigated deeply, ${ }^{23}$ including how to identify every element, ensure the proper composition, and produce accurate and stable nano-catalysts.

Self-assembly (SAM) offers customized design, controllable orientation, ease of recovery and stable monolayers. It also has the advantages of homogeneity and heterogeneity through the ingenious design of single-molecular structures. ${ }^{24}$ Previous studies have shown that the catalytic activity of the heterobimetallic catalysts could be enhanced by tuning their composition, morphology and the relative distributions of electrons, which are related to the electrical characteristics of the ligand, supports, and the synergy of hetero-bimetals. ${ }^{25-39}$ Appropriate supports could promise a high dispersion of metallic catalyst 
and the maximum utilization of noble materials has attracted much attention; ${ }^{\mathbf{1 9 4 0}}$ graphene oxide (GO) has been recognized as an ideal candidate for supporting various metals and their complexes. ${ }^{41-43} \mathrm{Pd}$ catalyst doped with $\mathrm{Ni}, \mathrm{Fe}$, $\mathrm{Co}$ or $\mathrm{Cu}$, reduces the loading of Pd and significantly enhances catalytic activity by adjusting the distance between nickel and palladium, charge distribution and the arrangement of active sites. ${ }^{34,36,44}$ Palladium was selected because of its efficient catalytic activity for Suzuki cross-coupling. However, its application was restricted by the limited reserves that were conventionally challenging for Pd catalysts. ${ }^{2}$ Nickel shares common chemical features and outer shell electron distribution with palladium. ${ }^{45,46}$ Crosscoupling reactions catalyzed by nickel have recently been attracting significant attention because of the lower toxicity, lower cost and greater nucleophilicity due to the smaller size of nickel as compared with Pd, which is critical for the Suzuki coupling reaction. Nickel cannot be simply considered to be a substitute for palladium since it possesses distinctive catalytic properties that palladium does not have. ${ }^{47,48}$ However, Ni is sensitive to solvent, a greater amount is needed, and severe catalytic conditions are usually required. ${ }^{49-65}$ The combination of the advantages of Pd and Ni for catalyzing the coupling reaction has recently attracted tremendous attention. ${ }^{66}$ The design of ordered, more cost-effective and eco-friendly forms to adjust catalytic properties and elucidate synergy is greatly needed. ${ }^{67-69}$

In this paper, the terpyridine group was selected as the binding site for palladium and nickel. The character of the terpyridine linkage with GO could provide the proper steric, coordination, and electronic requirements, leading to the bimetallic catalyst demonstrating high catalytic performance. The terpyridine $\mathrm{Pd} / \mathrm{Ni}$ catalytic monolayer fixed on the graphene oxide nano-sheet was prepared and its catalytic performance and the synergistic effects between different metals were systematically investigated.

\section{Experimental}

\subsection{Reagents and instruments and general procedure}

Chemical reagents and instruments used for characterization, general synthesis and the general procedure for the coupling reaction and RactIR recording are provided in the ESI. $\dagger$

\subsection{Preparation and characterization of GO@Tpy-Ni/Pd nano-sheets}

The main target here was that the two different metals were arranged in monolayers, which were mutually improved to form higher active species that were different from both individuals. The designed bimetallic catalytic monolayer was fabricated as shown in Scheme 1. Characterization was as follows:

FT-IR spectra of GO, GO@APTES, GO@Tpy and GO@Tpy-Pd/ $\mathrm{Ni}$ were obtained (Fig. S1 $\dagger$ ). Various peaks for $\mathrm{C}-\mathrm{O}\left(1053 \mathrm{~cm}^{-1}\right)$, $\mathrm{C}=\mathrm{O}\left(1726 \mathrm{~cm}^{-1}\right), \mathrm{C}=\mathrm{C}\left(161 \mathrm{~cm}^{-1}\right),=\mathrm{C}-\mathrm{H}\left(1381 \mathrm{~cm}^{-1}\right)$ and a broad peak from 3000 to $3500 \mathrm{~cm}^{-1}(-\mathrm{OH})$ revealed the existence of the carboxyl group, hydroxyl group, and epoxy group on GO. ${ }^{70}$ Compared with GO, the grafted ligand and

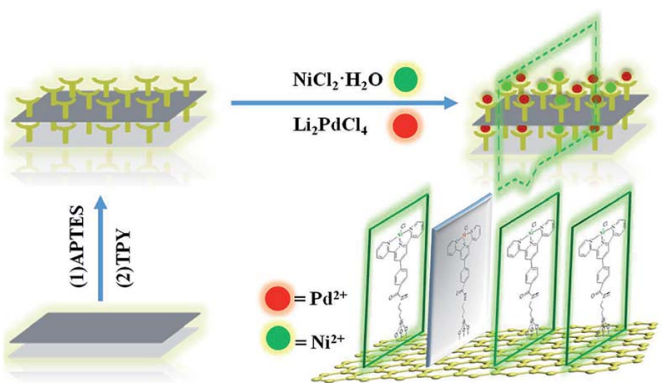

Scheme 1 Preparation route of GO@Tpy-Pd/Ni nano-sheets.

organometallic compounds could be identified by observing the changes in the functional groups at different steps. After GO was modified with APTES, $\mathrm{Si}-\mathrm{O}-\mathrm{C}$ and $\mathrm{Si}-\mathrm{O}-\mathrm{Si}$ peaks appeared at $1026 \mathrm{~cm}^{-1}$ and $1110 \mathrm{~cm}^{-1}$, providing evidence of silylanization to give GO@APTES. ${ }^{71}$ The band for the stretching vibration of $\mathrm{C}=\mathrm{N}$ was observed at $1614 \mathrm{~cm}^{-1}$, suggesting that terpyridine derivatives were linked with GO to yield GO@Tpy. The $\mathrm{C}=\mathrm{N}$ peak in GO@Tpy was red shifted after coordinating with Ni/Pd solution, attributed to the electron delocalization of $\mathrm{C}=\mathrm{N}$ due to coordination with metals to form GO@Tpy-Pd/Ni.

The intensity ratio of $\mathrm{D} / \mathrm{G}$ in RS provides important information. ${ }^{72}$ The Raman spectra of GO, GO@APTES, GO@Tpy and GO@Tpy-Pd/Ni were measured (Fig. $\mathrm{S} 2 \dagger$ ). The $I_{\mathrm{D}} / I_{\mathrm{G}}$ ratio for $\mathbf{G O}$ was about 0.94, while those for GO@APTES, GO@Tpy and GO@Tpy-Pd/Ni were $0.98,1.03$ and 1.02, respectively. This suggested that more numerous but smaller $\mathrm{sp}^{2}$ carbon domains were introduced into GO and the graphene lattice became a little disordered after modification. ${ }^{73}$

GO, GO@APTES, GO@Tpy and GO@Tpy-Pd/Ni were also characterized by XRD (Fig. S3 $\dagger$ ). The XRD pattern of GO showed a peak at $10.4^{\circ}$ due to the functional groups introduced. ${ }^{74}$ The XRD patterns of GO@APTES, GO@Tpy and GO@Tpy-Pd/Ni showed a broad peak at $2 \theta=21^{\circ}$, confirming that the major oxygen-containing groups of GO were functionalized. Moreover, the diffraction peak at around $10.1^{\circ}$ did not vanish, indicating that the structure of GO was not destroyed during the fabrication process. ${ }^{75}$

SEM and TEM images of GO, GO@APTES, GO@Tpy and GO@Tpy-Pd/Ni were obtained (Fig. S4 $\dagger$ ). It was apparent that the nano-sheets were layered structures that were closely associated with each other. ${ }^{56}$ The SEM images showed extending sheets of lateral dimensions ranging from a few to ten micrometers (Fig. S4A $\dagger$ ). The SEM image of GO@APTES (Fig. S4B †), GO@Tpy (Fig. S4C †) and GO@Tpy-Pd/Ni (Fig. S4D †) also presented neat sheet-like structures, demonstrating that the ordered Pd/Ni monolayer was modified on GO. Moreover, other sheet-like structures were observed (Fig. S4E $\dagger$ ). The TEM images of different steps were also measured (Fig. S4F-H†). The layer-like sheet of GO could also be observed, which was the evidence that the morphology of GO did not change during the modification steps. The catalysts having thin crumpled flakes with wrinkles and many folded regions made it easy for the substrate to access many active sites. 
Table 1 Resonance frequency changes in the Au@Tpy-Pd/Ni nanosheet

\begin{tabular}{llll}
\hline Entry & Self-assembly operation & Frequency $(F) / \mathrm{Hz}$ & $\Delta F / \mathrm{Hz}$ \\
\hline 1 & Au & 9983673 & - \\
2 & Au@OH & 9983602 & $\downarrow 71$ \\
3 & Au@APTES & 9981510 & $\downarrow 2092$ \\
4 & Au@Tpy & 9977622 & $\downarrow 3888$ \\
5 & Au@Tpy-Pd/Ni & 9974864 & $\downarrow 2758$
\end{tabular}

QCM is a useful method in on-line chemical and biological detection through monitoring the change in the mass on the surface of quartz, which also has the advantages of real-time online detection, high sensitivity, and easy operation. ${ }^{76,77}$ The detection principle is as follows:

$$
\Delta F=-2 F_{0} 2(\rho q \mu q)-1 / 2 \Delta m / A,-\Delta F \propto \Delta m .
$$

QCM was utilized to analyze the preparation process of Au@Tpy-Pd/Ni to simulate the preparation process of GO@Tpy$\mathbf{P d} / \mathbf{N i}$. The results are listed in Table 1.

The frequency of the bare quartz wafer was $9998673 \mathrm{~Hz}$. During the processes of silanization modification, ligand grafting and metal complexing, the frequency decreased by $71 \mathrm{~Hz}, 2092 \mathrm{~Hz}$ and $3888 \mathrm{~Hz}, 2758 \mathrm{~Hz}$, respectively. The results illustrated that the quality of the quartz wafer increased during the self-assembly process, which also demonstrated that each self-assembly step on the quartz wafer went on.

The chemical elements in the preparation process of GO@Tpy-Pd/Ni were also measured by XPS analysis (Fig. S5 $\dagger$ ). The peaks of $\mathrm{C} 1 \mathrm{~s}$ and $\mathrm{O}$ 1s were detected in GO. Si 2p, Si $2 \mathrm{~s}$, and $\mathrm{N}$ 1s were clearly detected after anchoring the terpyridine ligand in GO@Tpy. Compared with GO@Tpy, characteristic Pd 3d peaks at $337.92 \mathrm{eV}$ and $343.22 \mathrm{eV}$ denoted the bonding energy (BE) of $\mathrm{Pd}(\mathrm{II})$ and the peaks at $855.27 \mathrm{eV}, 861.62 \mathrm{eV}$, $873.42 \mathrm{eV}$, and $878.54 \mathrm{eV}$, assigned to the $\mathrm{BE}$ of $\mathrm{Ni}(\mathrm{II})$, were detected for GO@Tpy-Pd/Ni (Fig. S6 $\dagger$ ). The characteristics presented above confirmed that the ordered self-assembly of Ni/Pd bimetallic catalytic nano-sheets was fabricated.

\section{Results and discussion}

\subsection{Investigation of the catalytic properties of GO@Tpy-Pd/} Ni nanosheets

3.1.1 Evolution of the catalytic performance of GO@TpyPd/Ni. The optimization conditions of Suzuki coupling reactions catalyzed by GO@Tpy-Pd $\mathbf{P} / \mathbf{N i}_{\mathbf{1}}$ were initially carried out by screening various solvents, time, bases, temperatures, catalyst loading and substrate usage. The results are summarized in Table S1. $\uparrow$ The best yield was obtained by using a $\mathrm{H}_{2} \mathrm{O} / \mathrm{EtOH}$ mixture ( $/ \mathrm{v}=1: 3$ ) (entries 1-8). The influence of base was also examined, in which $\mathrm{K}_{2} \mathrm{CO}_{3}$ provided the best yield (95\%) (entries 7 and 9-11). In addition, $35^{\circ} \mathrm{C}$ and $8 \mathrm{~h}$ were determined to be the optimum conditions (entries 12-15). With different

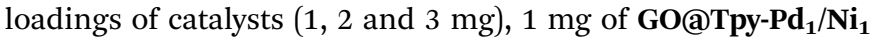

was the optimized loading (entries 16-17) and the usage of substrate was examined, in which 4-bromotoluene $(0.3 \mathrm{mmol})$ was the best loading (entries 18-19). Based on the results, the best catalytic conditions were $\mathrm{K}_{2} \mathrm{CO}_{3}$ as the base, the $\mathrm{H}_{2} \mathrm{O} / \mathrm{EtOH}$ mixture (v/v = $1: 3)$ as the solvent, GO@Tpy-Pd $\mathbf{P} / \mathbf{N i}_{\mathbf{1}}$ catalyst (1 $\mathrm{mg})$, 4-bromotoluene ( $0.35 \mathrm{mmol}), 35{ }^{\circ} \mathrm{C}$, and $8 \mathrm{~h}$. These were used in further investigations.

3.1.2 The effect of composition on the catalytic properties of GO@Tpy-Pd/Ni $\mathbf{N}_{\boldsymbol{x}}$. Employing optimized conditions, the effect of composition on the performance of GO@Tpy-Pd/Ni $\mathbf{i}_{\boldsymbol{x}}$ was investigated and the results are listed in Table S2.† Among the three compositions tested, the catalytic yield of GO@Tpy-Ni was only as low as $17 \%$. However, by doping palladium with nickel, the reactivity could be significantly improved, in which GO@Tpy-Pd $\mathbf{P} / \mathbf{N i}_{\mathbf{1 0}}$ provided the best performance. Thus, it was likely that the proper ratio of palladium to nickel on the surface could effectively create a favourable micro-environment to promote catalytic activity. Also, doping with another metal exhibited electronic or steric effects that impacted its catalytic performance by a "cooperative effect". ${ }^{78}$ This also implied that proper active sites on the surface could efficiently contact the substrates and catalyze the reaction.

3.1.3 Substrate scoping in the Suzuki coupling reaction catalyzed by GO@Tpy-Pd $\mathbf{1} / \mathbf{N i}_{\mathbf{1 0}}$. Under optimized conditions, Suzuki coupling reactions catalysed by $\boldsymbol{G O} @ \mathbf{T p y}-\boldsymbol{P d _ { 1 }} / \mathbf{N i} \boldsymbol{i}_{10}$ with various aryl halides and arylboronic acids were carried out. The results are depicted in Table S3. $\uparrow$ The coupling reactions proceeded with electron-withdrawing and electron-donating aryl bromide and arylboronic acids to give biaryl products with high yields (Table S3, $\uparrow$ entries 1-6). However, in the case of aryl chlorides, lower yields were obtained (entries 7 and 8). Coupling product could also be obtained in the case of benzyl bromide with naphthylboronic acid in high yield (entry 9), except with the thiophene derivative (entry 10) due to its poisoning properties toward active sites. These results showed that GO@Tpy$\mathbf{P d}_{\mathbf{1}} / \mathbf{N i}_{\mathbf{1 0}}$ was an active Ni/Pd bimetallic catalyst for the synthesis of aromatic compounds with higher TON value.

3.1.4 The influence of supports and functional structure on the catalytic performance. Comparison experiments were designed and carried out to investigate the effects of supports on catalytic properties (Table 2).

Coupling compounds were not detected by GO (entry 1). In the case of a simple mixture of $\mathrm{Li}_{2} \mathrm{PdCl}_{4}$ and $\mathrm{NiCl}_{2}$, only $14 \%$ yield was obtained (entry 2). When a mixture of ligand, $\mathrm{Li}_{2} \mathrm{PdCl}_{4}$ and $\mathrm{NiCl}_{2}$ without $\mathbf{G O}$ was used, $31 \%$ yield was obtained (entry 3). For GO@Tpy-Ni (entry 5), Gel@Tpy-Pd/Ni (entry 7) and Glass@Tpy-Pd/Ni (entry 8), lower yields were obtained, which showed poor activity as compared with GO@Tpy-Pd (entry 4) or GO@Tpy-Pd $\mathbf{1} / \mathbf{N i}_{10}$ (entry 6). GO@Tpy-Pd $\mathbf{P} / \mathbf{N i}_{10}$ also showed higher activity than GO@Tpy-Pd, although the Pd content of GO@Tpy-Pd $\mathbf{H}_{\mathbf{1}} / \mathbf{N i}_{\mathbf{1 0}}$ was one fourth that of GO@Tpy-Pd. It was evident that the $\mathbf{P d} / \mathbf{N i}$ catalyst could enhance its activity due to the ordered orientation and synergy between nickel and palladium. The TOF value of GO@Tpy-Pd $\mathbf{1} / \mathbf{N i}_{\mathbf{1 0}}$ was 5 times and 3 times greater than that of Glass@Tpy-Pd/Ni and Gel@Tpy-Pd/Ni (entry 7), respectively. This result clearly revealed that GO also had a great role in the activity. ${ }^{79,80}$ The role of GO containing the 
Table 2 Effects of supports on catalytic properties ${ }^{a}$

\begin{tabular}{|c|c|c|c|c|c|}
\hline Catalyst & Pd loading $\left(\mathrm{mol} \mathrm{g}^{-1}\right)$ & Ni loading $\left(\mathrm{mol} \mathrm{g}^{-1}\right)$ & Molar ratio (Pd/Ni) & Yield $^{b} / \%$ & TON \\
\hline GO & - & - & - & 0 & 0 \\
\hline $\mathrm{NiCl}_{2} / \mathrm{Li}_{2} \mathrm{PdCl}_{4}$ & $1.80 \times 10^{-5}$ & $3.00 \times 10^{-5}$ & $1: 1.70$ & 14 & 2333 \\
\hline GO@Tpy-Pd & $7.11 \times 10^{-5}$ & - & - & 91 & 3839 \\
\hline GO@Tpy-Ni & - & $3.28 \times 10^{-5}$ & - & 17 & 1555 \\
\hline GO@Tpy-Pd $1 / \mathbf{N i}_{10}$ & $1.82 \times 10^{-5}$ & $2.93 \times 10^{-5}$ & $1: 1.60$ & 96 & 15824 \\
\hline
\end{tabular}

${ }^{a}$ Reaction conditions: $\mathrm{PhB}(\mathrm{OH})_{2}(0.35 \mathrm{mmol}), 4$-bromotoluene $(0.3 \mathrm{mmol})$, base $(0.6 \mathrm{mmol}), \mathbf{G O} @ \mathbf{T p y}-\mathbf{P d}_{\mathbf{1}-\boldsymbol{x}} / \mathbf{N i}_{\boldsymbol{x}}: 1 \mathrm{mg}$ solvent $(5.0 \mathrm{~mL})$ at $35{ }^{\circ} \mathrm{C}$ for 8 h. ${ }^{b}$ Isolated yield.

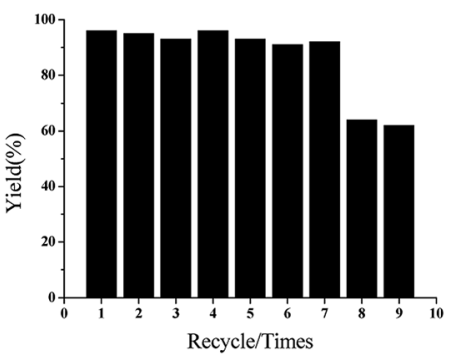

Fig. 1 The recycling experiments of GOCTpy- $\mathrm{Pd}_{1} / \mathrm{Ni}_{10}$ for the Suzuki coupling reaction.

functional groups is to disperse and stabilize the bimetallic catalyst, which makes it more favorable for substrates to access the active center because of its two-dimensional configuration and the major interaction of the two metals. This led to efficient electron transfer between the supports, ligand and the catalytic

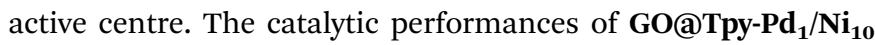
were also compared with the literature (Table $\mathrm{S} 4 \dagger$ ).

3.1.5 Stability and recycling experiment. To further inves-

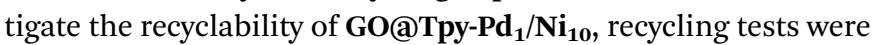
performed (Fig. 1). After the sixth run, high activity without a discernible loss could be maintained. However, lower yields were observed in seven cycles (61\%). When the time was extended to $12 \mathrm{~h}$ in the eighth cycle, the yield increased to $85 \%$. Unfortunately, in the ninth cycle, the yield again dropped to $64 \%$, suggesting that the deactivation of the catalyst occurred in the catalytic process. ${ }^{36-39}$ In particular, when the freshly prepared GO@Tpy-Pd $\mathbf{P} / \mathbf{N i}_{\mathbf{1 0}}$ was exposed for 1 month under

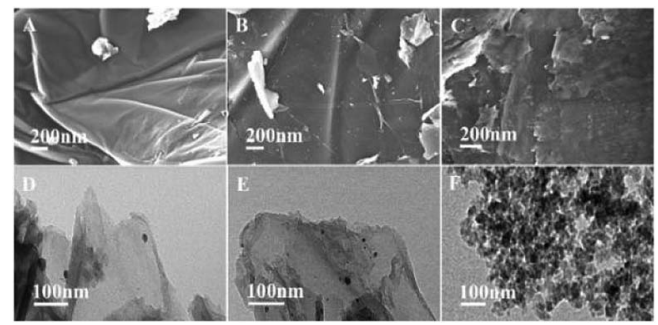

Fig. 2 SEM and TEM images of GOQTpy- $\mathrm{Pd}_{1} / \mathrm{Ni}_{10}(A$ and $\mathrm{D})$ fresh catalyst, ( $\mathrm{B}$ and $\mathrm{E})$ after the 1st run, ( $\mathrm{C}$ and $\mathrm{F}$ ) after the 6 th run. ambient conditions, $90 \%$ yield could be obtained for the model

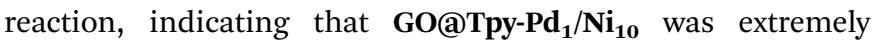
stable.

To determine the decay mechanism, the changes in the catalyst during the catalytic process were characterized by TEM and SEM (Fig. 2). SEM and TEM after the 1st run showed no obvious changes in the surface morphology (Fig. 2B and E) as compared with the fresh catalyst (Fig. 2A and D). However, there was a clear accumulation on the catalytic surface after six cycles (Fig. 2C and F), which might be unavoidable for most supported metallic catalysts under such reaction conditions. Therefore, we speculated that the decrease in the activity might be due to the aggregation of active species, indicating that it was a structuresensitive catalytic reaction. ${ }^{\mathbf{8 1}}$ The Pd and Ni content in GO@Tpy$\mathbf{P d}_{\mathbf{1}} / \mathbf{N i}_{\mathbf{1 0}}$ recycled for seventh was also measured, in which 1.34 $\times 10^{-6} \mathrm{~mol} \mathrm{~g}^{-1}$ and $1.48 \times 10^{-7} \mathrm{~mol} \mathrm{~g}^{-1}$ were determined for palladium and nickel, respectively. It indicated that the leaching of metals was also one of the reasons for loss activity.

\subsection{Investigation of the catalytic mechanism}

3.2.1 Hot filtration experiment. It is well known that it is important to distinguish heterogeneous catalysts from homogeneous catalysts. The yield increased rapidly before $2 \mathrm{~h}$ and then increased slowly after $2 \mathrm{~h}$ (Fig. 3, black line). The reaction was finished in $8 \mathrm{~h}$ with a $93 \%$ yield. The high activity of the GO@Tpy-Pd $\mathbf{P} / \mathbf{N i}_{\mathbf{1 0}}$ was attributed to the favorable configuration and dispersion ability. In order to explore whether Pd leaching occurred during the catalytic process, GO@Tpy-Pd $\mathbf{P} / \mathbf{N i}_{\mathbf{1 0}}$ was

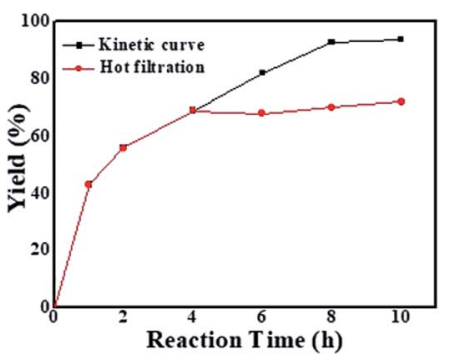

Fig. 3 Kinetic curve and hot filtration experiment for GOQTpy- $\mathrm{Pd}_{1} /$ $\mathrm{Ni}_{10}$. 
removed from the solution in $4 \mathrm{~h}$ and the yields were monitored. The yield showed no increase, remaining almost constant (69-71\%, Fig. 4, red line), which indicated that no Pd leaching into solution occurred during the catalytic reaction process. ${ }^{35,38}$

3.2.2 Poisoning tests. To elucidate the sites on which the catalysis proceeded, poisoning tests were designed and the results are summarized in Table $S 5 . \dagger$ When a little mercury was added to the catalytic system, only $14 \%$ yield was obtained because the limited active centres on the surface of the catalytic nano-sheet could be partially covered by strong poisons in substoichiometric amounts of $\mathrm{Hg}$ due to the poor dispersibility of mercury. When thiophene additives were used, even with less than 1.0 equivalent, significant loss of activity was noted due to the strong chemisorption of thiophene on catalytic centres, thus blocking sites for catalytic reaction. ${ }^{82}$ The results provided evidence that the catalysis mainly proceeded on the surface of GO@Tpy-Pd $/ \mathbf{N i}_{10}$.

3.2.3 Quartz crystal microbalance (QCM) monitoring. Quartz crystal microbalance (QCM) has the advantages of realtime online detection, high sensitivity, and easy operation. ${ }^{76,77}$ For further insight into the catalytic mechanism, the Au@Tpy$\mathbf{P d}_{\mathbf{1}} / \mathbf{N i}_{\mathbf{1 0}}$ self-assembled monolayer was fabricated on the quartz wafer with which the frequency change was detected during the catalysis. As shown in Fig. 4, the frequency of Au@Tpy-Pd $\mathbf{A} / \mathbf{N i}_{\mathbf{1 0}}$ showed the "decrease and increase". The change in frequency within 700-1300 s was more significant than that during 1300$1700 \mathrm{~s}$. Correspondingly, the quality change on the quartz presented the "increase and decrease" in the catalytic process. This phenomenon indicated that adsorption and desorption occurred. It was clear that the rate of adsorption in the first half was greater than that of desorption, and the desorption rate in the second half was greater than that of adsorption. Finally, the adsorption and desorption reached an equilibrium. The results clearly showed the changes during the catalytic process, which indicated the absorption and desorption processes.

3.2.4 In situ Fourier transform infrared (FTIR) spectroscopy monitoring. The ReactIR 3D maps over time by GO@TpyPd1/Ni10 (Fig. 5A) and $\mathrm{Li}_{2} \mathrm{PdCl}_{4} / \mathrm{NiCl}_{2} \cdot 6 \mathrm{H}_{2} \mathrm{O}$ (Fig. 5B) showed a marked difference. For GO@Tpy-Pd1/Ni10, the peak intensity at $754 \mathrm{~cm}^{-1}$ assigned to the coupling product, had no significant change from 0 to $10 \mathrm{~min}$ and increased rapidly with time. The final kinetic curve was "S"-shaped until the reaction was completed, which indicated the characteristic heterogeneous catalysis (Fig. 5C, black line). ${ }^{36,83}$ This could be because the

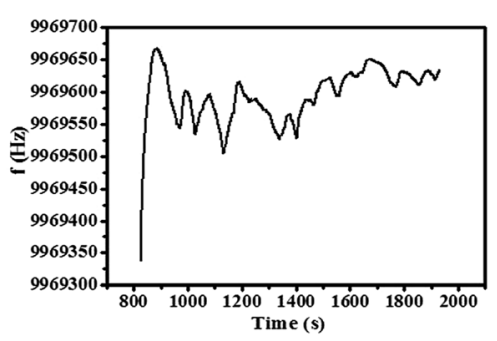

Fig. 4 QCM responses of the sensor in the Suzuki reaction process catalyzed by Au@Tpy-Pd1/Ni10.
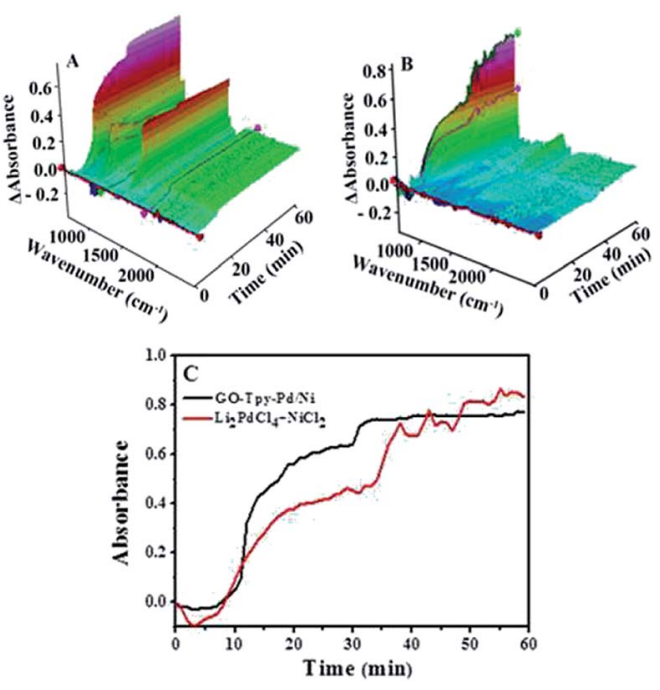

Fig. 5 ReactIR plots over time for the formation of 4-phenyltoluene: (A) 3D map of by GOQTpy- $\mathrm{Pd}_{1} / \mathrm{Ni}_{10}$; (B) 3D map of $\mathrm{Li}_{2} \mathrm{PdCl}_{4} / \mathrm{NiCl}_{2}-$ - $6 \mathrm{H}_{2} \mathrm{O}$; (C) kinetic analysis of the reaction catalyzed by $\mathrm{GOQTpy}-\mathrm{Pd}_{1} /$ $\mathrm{Ni}_{10}$ and $\mathrm{Li}_{2} \mathrm{PdCl}_{4} / \mathrm{NiCl}_{2} \cdot 6 \mathrm{H}_{2} \mathrm{O}$ using the band at $754 \mathrm{~cm}^{-1}$. Reaction conditions: $\mathrm{PhB}(\mathrm{OH})_{2}(1 \mathrm{mmol}), 4$-bromotoluene $(1.5 \mathrm{mmol})$, base (2 $\mathrm{mmol})$, solvent $(6 \mathrm{~mL}), 35^{\circ} \mathrm{C}, 1 \mathrm{~h}$.

surface of the catalytic monolayer contained a limited number of active centres. The substrates were first adsorbed on the surface without any reaction, which was called an "induced period". Then, the intermediates were generated by reacting the substrate with specific active sites. Finally, the products were formed and diffused to the reaction solution from the catalytic surface. This was consistent with QCM detection.

When the same amount of $\mathrm{Li}_{2} \mathrm{PdCl}_{4} / \mathrm{NiCl}_{2} \cdot 6 \mathrm{H}_{2} \mathrm{O}$ was used, no coupling product was observed because of the limitation of the amount of catalyst, which indicated that the orientation and distribution of active centres were crucial factors in catalysis. When a greater amount was added, the peak intensity of the product gradually increased within 10-35 minutes and rapidly increased until it reached equilibrium, in which the trend showed a "step" shape (Fig. 5C, red line); however, its intensity was lower than that of GO@Tpy-Pd $\mathbf{1} / \mathbf{N i} \mathbf{i}_{\mathbf{1 0}}$. This provided

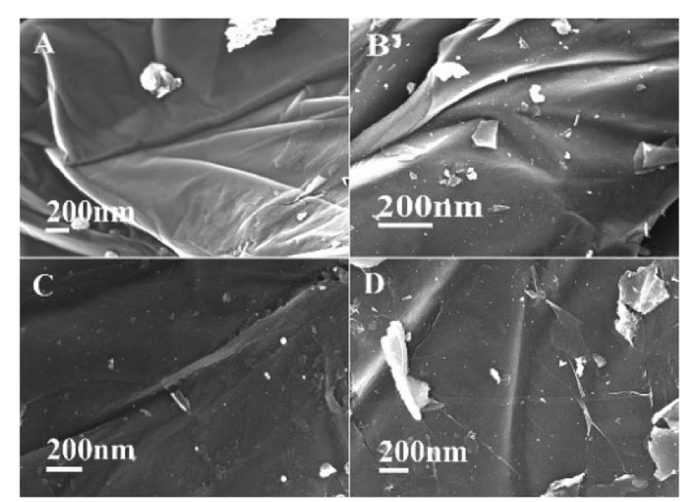

Fig. 6 SEM images of GOQTpy- $\mathrm{Pd}_{1} / \mathrm{Ni}_{10}$ at (A) $0 \mathrm{~h}$, (B) $2 \mathrm{~h}$, (C) $4 \mathrm{~h}$, and (D) $8 \mathrm{~h}$. 
evidence that the ordered bimetallic monolayer had a higher catalytic activity under the same conditions.

3.2.5. SEM and TEM images of GO@Tpy-Pd1/Ni10 in the catalytic process. The surface morphology changes in the catalyst during the catalytic process were characterized by SEM and TEM. Compared with the GO@Tpy-Pd $\mathbf{1} / \mathbf{N i}_{\mathbf{1 0}}$, the surface was still a lamellar folded structure after $2 \mathrm{~h}, 4 \mathrm{~h}$, and $8 \mathrm{~h}$ and remained in the basic morphology as shown in Fig. 6. It could be concluded that the designed GO@Tpy-Pd $\mathbf{P} / \mathbf{N i}_{\mathbf{1 0}}$ was structurally stable during the catalytic process.

Correspondingly, TEM images of GO@Tpy-Pd $\mathbf{1} / \mathbf{N i}_{\mathbf{1 0}}$ show a wrinkle-like two-dimensional thin-layer structure (Fig. 7) and nano-sized particles were generated due to the formation of palladium-nickel metal elements after 2 hours and 4 hours. This could be related to the aggregation of the catalytic species to form Ni/Pd clusters due to the migration of active atoms by coupling with each other through complex physicochemical processes during catalysis. ${ }^{82}$

3.2.6 XPS investigation of GO@Tpy-Pd1/Ni10 in the catalytic process. The XPS survey spectrum and $\mathrm{N} 1 \mathrm{~s}, \mathrm{Pd} 3 \mathrm{~d}$, B $1 \mathrm{~s}$ and $\mathrm{Br}$ 3d XPS spectra of GO@Tpy-Pd $\mathbf{P}_{\mathbf{1}} / \mathbf{N i}_{\mathbf{1 0}}$ during the catalytic process were obtained (Fig. 8). For the GO@Tpy-Pd $\mathbf{P} / \mathbf{N i}_{\mathbf{1 0}}$, a pair of Pd $3 \mathrm{~d}_{3 / 2}$ and $\mathrm{Pd} 3 \mathrm{~d}_{5 / 2}$ peaks appeared at $340.74 \mathrm{eV}$ and $335.14 \mathrm{eV}$, assigned to $\mathrm{Pd}(0)$ after $2 \mathrm{~h}$ (Fig. 8B), and the intensity of $\operatorname{Pd}(0)$ gradually increased with time. In contrast, the intensity of $\mathrm{Pd}(\mathrm{II})$ gradually decreased during the catalytic procedure, meaning that a little $\mathrm{Pd}(\mathrm{II})$ was reduced to $\mathrm{Pd}(0)$, which was the real active centre. The intensity of $\operatorname{Pd}(0)$ almost disappeared at the end, and the intensity of the $\operatorname{Pd}(\mathrm{II})$ peak gradually recovered, suggesting that $\operatorname{Pd}(0)$ might be oxidized to $\operatorname{Pd}(\mathrm{II})$. During this process, the $\mathrm{N} 1 \mathrm{~s}$ energy level peak had also undergone certain changes (Fig. 8A), in which the $\mathrm{N}$ 1s peak appeared at $399.6 \mathrm{eV}$ before catalysis. However, the N 1s peaks shifted to $400.29 \mathrm{eV}$ (1 h), $400.44 \mathrm{eV}(4 \mathrm{~h})$ and $399.98 \mathrm{eV}(8 \mathrm{~h})$ during the reaction. It was not difficult to find that the position of the $\mathrm{N} 1 \mathrm{~s}$ peak in the catalytic process showed a trend of first increasing and then decreasing. This was due to the electron transfer caused by the change in the valence state during the reaction between palladium and nickel that were coordinated with metals. Interestingly, B $1 \mathrm{~s}$ and $\mathrm{Br} 3 \mathrm{~d}$ were detected at $1 \mathrm{~h}$ and $4 \mathrm{~h}$, but no B $1 \mathrm{~s}$ and $\mathrm{Br} 3 \mathrm{~d}$ at the end (Fig. $8 \mathrm{C}$ and D). Metal elements were generated after starting catalysis and the oxidation of benzyl

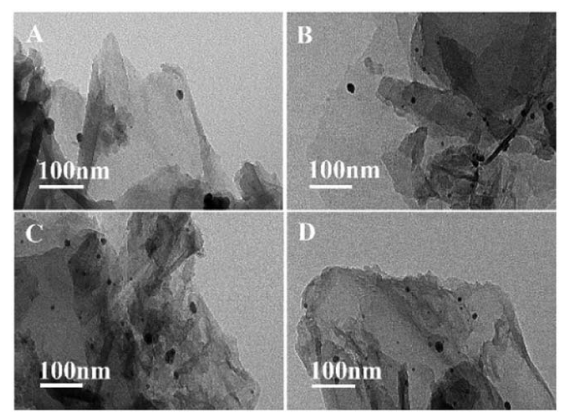

Fig. 7 TEM images of GOQTpy- $\mathrm{Pd}_{1} / \mathrm{Ni}_{10}$ for catalysis at (A) $0 \mathrm{~h}$, (B) $2 \mathrm{~h}$, (C) $4 \mathrm{~h}$, (D) $8 \mathrm{~h}$.

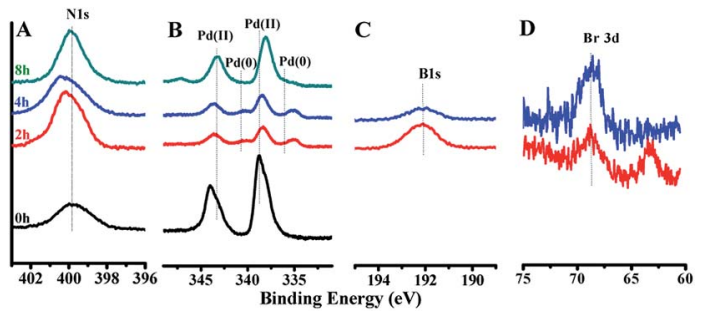

Fig. 8 XPS of (A) N 1s, (B) Pd 3d, (C) B 1s and (D) Br 3d at O h, 2 h, 4 h, and $8 \mathrm{~h}$.

bromide with metal to give intermediate $\mathbf{B r}-\mathbf{P d}-\mathbf{P h}$ inside or on the surface. Afterwards, reduced elimination was achieved by phenylboronic acid with intermediates to yield the coupling product on removing $\mathrm{B}$ and $\mathrm{Br}$ from the surface.

The energy level change in $\mathrm{Ni} 2 \mathrm{p}$ during the catalytic process was also analyzed (Fig. 9) and the binding energy of the Ni 2p energy peak was reduced after $2 \mathrm{~h}$. The $\mathrm{Ni} 2 \mathrm{p}_{3 / 2}$ energy level peak and its satellite peak appeared at $852.84 \mathrm{eV}$ and $863.34 \mathrm{eV}$ after $4 \mathrm{~h}$, which was attributed to $\mathrm{Ni}(0)$ being generated due to electron transfer from GO. This could be in the form of several atoms-clusters $\mathrm{Ni} / \mathrm{Pd}$ during this time, which made it easy for the oxidation step because of much more negative active centres (Scheme 2). The binding energy of the Ni $2 p$ energy level peak gradually returned to the pre-reaction state after $8 \mathrm{~h}$ and $\mathrm{Ni}(0)$ was oxidized to Ni(II). Regarding the XPS spectra of Ni 2p and Pd $3 \mathrm{~d}$, the atomic cluster of $\mathrm{Ni}(0) / \mathrm{Pd}(0)$ surrounded by appropriate $\mathrm{Pd}(\mathrm{II}) / \mathrm{Ni}(\mathrm{II})$ played a significant role in the catalysis due the synergistic effect, being mainly responsible for its higher activity. It was clear that the clusters were coordinated with ligand mostly at the surface of the organometallic framework. The surface can be regarded as an infinite "organometallic pool" containing a few active species ${ }^{84}$ showing the great impact of the modification of a metallic surface by organometallic compounds on its catalytic properties.

The activity of the catalyst depended on the real active sites on the catalytic surface which were affected by the structure of

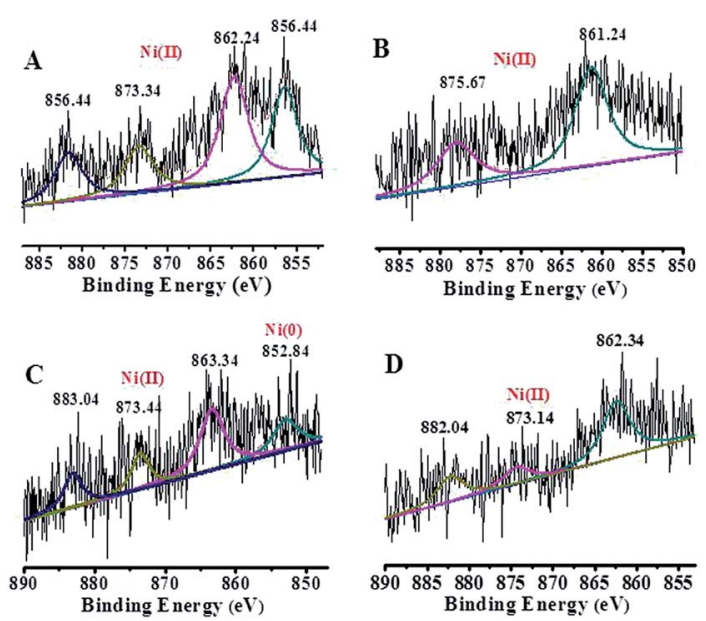

Fig. 9 High-resolution XPS of Ni $2 p$ at different times: (A) $0 h$, (B) $2 \mathrm{~h}$, (C) $4 \mathrm{~h}$, and (D) $8 \mathrm{~h}$. 


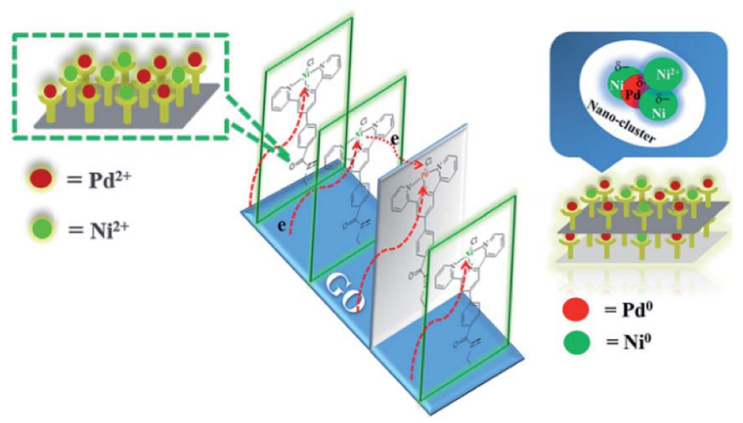

Scheme 2 Proposed formation of the active centre Ni/Pd cluster during the catalytic process.

the ligand and possibilities of electron transfer. In this catalytic monolayer, graphene oxide sheet itself showed some major possibilities of electron transfer and promoted the catalytic activity. The different possibilities of electron transfer in GO@Tpy-Pd $\mathbf{1} / \mathbf{N i}_{\mathbf{1 0}}$ were as follows: (i) $\mathrm{Ni}$ (II) to adjacent Pd(II); (ii) $\mathrm{Ni}($ II) passed through adjacent graphene nanolayers to adjacent Pd(II); (iii) Pd(II), Ni(II) to the adjacent carbon atom/graphene nano-sheet. The number of different ways for electron transfer depicted in GO@Tpy-Pd $\mathbf{H}_{\mathbf{1}} / \mathbf{N i}_{\mathbf{1 0}}$ was considerably higher as compared to the mono-metallic GO@Tpy-Pd and Si@Tpy-Pd 1 / $\mathbf{N i}_{1}$ catalyst.

In order to further investigate the synergy between palladium and nickel presented during the catalytic reaction, density functional theory was utilized to calculate the energy barrier of the oxidative insertion process catalyzed by $\mathrm{Pd}(0)$ and $\mathrm{Ni}(0)$. The Pd-Br, Pd-C and C-Br distances were 3.13, 2.00, and $2.26 \AA$ in transition state TS1, and the energy barrier of the oxidative insertion was $3.6 \mathrm{kcal} \mathrm{mol}^{-1}$ (Fig. $\mathrm{S} 7 \dagger$ ). The $\mathrm{Ni}-\mathrm{Br}, \mathrm{Ni}-\mathrm{C}$ and $\mathrm{C}-$ Br distances were 2.84, 2.54 and $2.12 \AA$ in transition state TS2, and the EB of the oxidative insertion was $17.8 \mathrm{kcal} \mathrm{mol}^{-1}$, which was higher than that of $\operatorname{Pd}(0)$ (Fig. S8 $\dagger$ ). The results showed that both $\operatorname{Pd}(0)$ and $\mathrm{Ni}(0)$ could form oxidation intermediates, although $\operatorname{Pd}(0)$ was much more active than $\mathrm{Ni}(0)$ in the oxidation step. The results were consistent with the experiments listed in Table 2.

One of the necessary steps during the catalytic reaction was the adsorption of one or more substrates. This was necessary for investigating the effects of the adsorbed substrates on the active species because it could help to elucidate the mechanism. The overall thinking was that the significant catalysts should integrate with substrates, intermediates or target molecules in certain concentrations to indicate whether the interaction force was too weak to activate the reactants and too strong to release the compounds. ${ }^{85}$ Thus, it provided a simple way to find the right metal combination in which different metals had various selectivities and functions, although many aspects must be simultaneously taken into account. ${ }^{86-88}$ DFT was used for investigating the absorption ability of the substrate and desorption ability of the product on different sites on the catalytic surface (Fig. S9†), by which the suitable selection of the bimetallic combination could be predicted..$^{89-92}$ The results are shown in Table S6, $\dagger$ which were calculated by DFT (Fig. S10†).

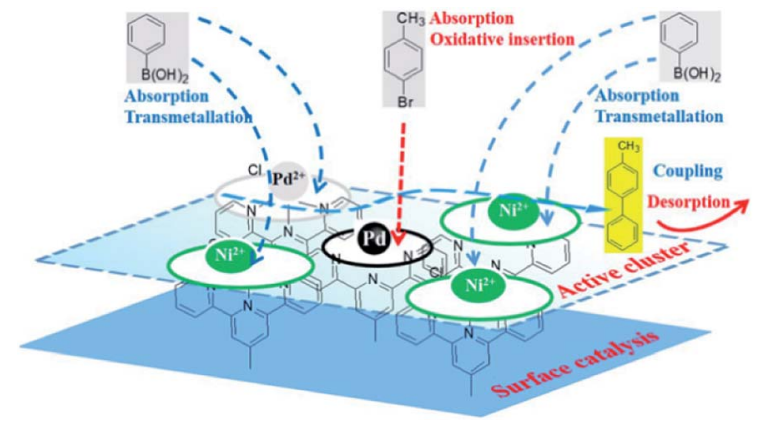

Scheme 3 Synergy among the active sites during the catalytic process in the self-assembly of the organometallic framework films (OMFFs).

$\operatorname{Pd}(0)$ had a higher absorption for $p$-bromotoluene and a weakened absorption for phenyl boronic acid as compared to $\mathrm{Pd}(\mathrm{II})$ and $\mathrm{Ni}(\mathrm{II})$, indicating that the oxidative insertion could be easily completed by $\operatorname{Pd}(0)$ with $p$-bromotoluene. On the other hand, $\mathrm{Pd}(\mathrm{II})$ or $\mathrm{Ni}(\mathrm{II})$ in the vicinity of $\mathrm{Pd}(0)$ had a higher absorption ability for phenyl boronic acid, which facilitated metallic transfer, with the oxidative insertion intermediate formed on the next-nearest neighbor $\operatorname{Pd}(0)$ site. $\mathrm{Pd}(\mathrm{II}), \mathrm{Ni}(\mathrm{II})$ and $\operatorname{Pd}(0)$ had similar absorption abilities for coupling compounds. The DFT results obtained above showed that $\mathrm{Pd}(0)$ presented the higher activity because of its higher activation toward $p$ bromotoluene, and weaker absorption for the products. Meanwhile, Pd(II) and Ni(II) showed their stronger absorption for phenyl boronic acid, which was helpful for metallic transfer, and lower absorption for the coupling compound, which diffused easily from the surface. It was evident that the bimetallic catalyst had higher activity than the single metallic catalyst due to their synergy in position, orientation or distributionselective processes, indicating that both active-sites and nonactive sites participated simultaneously in the catalytic process as shown in scheme 3. The presumed processes confirmed by DFT were consistent with the XPS variation during the catalytic process as shown in Fig. 9. We propose that new adsorption sites were likely formed with different electron densities, strengthening $p$-bromotoluene adsorption for $\mathrm{Pd} / \mathrm{Ni}$, which made $\operatorname{Pd}(0)$ compete more efficiently for adsorption sites in the form of the co-adsorption of phenyl boron acid and $p$-bromotoluene adsorption; therefore, nickel was considered as a promoter. ${ }^{93}$ This also suggests that $\mathrm{Pd}(0) / \mathrm{Ni}(0)$ and $\mathrm{Pd}(\mathrm{II}) / \mathrm{Ni}(\mathrm{II})$ are not mutually exclusive, but have synergistic interactions as whole, indicating that one can consider that active clusters adopt a coordination sphere already present in the organometallic catalyst surface. ${ }^{19}$ This could be called the self-assembly organometallic framework nano-sheet (OMFNS), in which the morphology of the organometallic surface, orientation of the organometallic framework in the monolayer, kinds of ligands, support selected, ratio of bimetal, and interaction between aryl groups were crucial to the activity and stability of the catalyst.

\section{Conclusion}

A new graphene oxide-supported $\mathrm{Ni} / \mathrm{Pd}$ terpyridine selfassembled catalytic monolayer (denoted as GO@Tpy-Ni/Pd) 
was fabricated, which exhibited higher catalytic activity, substrate applicability and recyclability as a heterogeneous catalyst for the Suzuki coupling reaction under mild conditions. QCM was used for characterizing and monitoring the reaction by the on-line detection of the frequency changes in a quartz wafer linked to the bimetallic catalyst, and clearly different rates of adsorption and desorption were presented during the catalytic process. The synergetic mechanism between nickel and palladium was investigated in detail, in which the atomic-scale cluster of Ni/Pd could be formed. The real active centre was the crucial factor that made it easy for the initial oxidation step to occur. The absorption and adsorption on the Ni/Pd clusters in the bimetallic Pd-Ni core-shell nanoparticles as effective catalysts for the Suzuki reaction surface for different substrates and products, as calculated by DFT, was also an important factor. This indicated that the synergy between the active site and the doped second metal made it easy for the initial oxidation step and trans-metallation to occur, by which the proper design of the catalyst, including the ligand, selection of the support, the suitable combination of metals and elucidation of the catalytic mechanism could be achieved.

\section{Conflicts of interest}

There are no conflicts to declare.

\section{Acknowledgements}

This work was supported by the NSFC (21861132002), the Henan Natural Science Foundation of China (192102210046) for their financial support. The authors thank Prof. Zhi Ma (Institute of Chemistry, Chinese Academy of Sciences, Shanghai) for Raman measurement.

\section{Notes and references}

1 B. H. Lipshutz, N. A. Isley, J. C. Fennewald and E. D. Slack, On the Way Towards Greener Transition-Metal-Catalyzed Processes as Quantified by E Factors, Angew. Chem., Int. Ed., 2013, 52, 10952-10958.

2 N. A. Isley, F. Gallou and B. H. Lipshutz, Transforming Suzuki-Miyaura Cross-Couplings of MIDA Boronates into a Green Technology: No Organic Solvents, J. Am. Chem. Soc., 2013, 135, 17707-17710.

3 T. Iwasaki and N. Kambe, Ni-Catalyzed C-C Couplings Using Alkyl Electrophiles, Top. Curr. Chem., 2016, 374(5), 66.

4 P. X. Xi, Y. Cao, F. C. Yang, C. Ma, F. J. Chen, S. Yu, S. Wang, Z. Z. Zeng and X. Zhang, Facile synthesis of Pd-based bimetallic nanocrystals and their application as catalysts for methanol oxidation reaction, Nanoscale, 2013, 5, 61246130.

5 F. Saleem, Z. C. Zhang, B. Xu, X. B. Xu, P. L. He and X. Wang, Ultrathin $\mathrm{Pt}-\mathrm{Cu}$ nanosheets and nanocones, J. Am. Chem. Soc., 2013, 135, 18304-18307.

6 Z. Wang, B. Li, X. Y. Zhang and X. S. Fan, One-Pot Cascade Reactions Leading to Pyrido $\left[2^{\prime}, 1^{\prime}: 2,3\right] \operatorname{imidazo}[4,5-\mathrm{c}][1,2,3]$ triazolo[1,5-a]quinolines under Bimetallic Relay Catalysis with Air as the Oxidant, J. Org. Chem., 2016, 81, 6357-6363.

7 J. Xiang, P. Li, H. B. Chong, L. Feng, F. Y. Fu, Z. Wang, S. L. Zhang and M. Z. Zhu, Bimetallic Pd-Ni core-shell nanoparticles as effective catalysts for the Suzuki reaction, Nano Res., 2014, 7(9), 1337-1343.

8 R. K. Rai, K. Gupta, S. Behrens, J. Li, Q. Xu and S. K. Singh, Highly Active Bimetallic Nickel-Palladium Alloy Nanoparticle Catalyzed Suzuki-Miyaura Reactions, ChemCatChem, 2015, 7, 1806-1812.

9 S. F. Cai, H. H. Duan, H. P. Rong, D. S. Wang, L. S. Li, W. He and Y. D. Li, Highly Active and Selective Catalysis of Bimetallic $\mathrm{Rh}_{3} \mathrm{Ni}_{1}$ Nanoparticles in the Hydrogenation of Nitroarenes, ACS Catal., 2013, 3, 608-612.

10 M. Ahmadi, F. Behafaid, C. H. Cui, P. Strasser and B. R. Cuenya, Long-range segregation phenomena in shape-Selected bimetallic nanoparticles: Chemical state effects, ACS Nano, 2013, 7, 9195-9204.

11 S. U. Son, Y. J. Jang, J. Park, H. B. Na, H. M. Park, H. J. Yun, J. Lee and T. Hyeon, Designed Synthesis of Atom-Economical $\mathrm{Pd} / \mathrm{Ni}$ Bimetallic Nanoparticle-Based Catalysts for Sonogashira Coupling Reactions, J. Am. Chem. Soc., 2004, 126, 5026-5027.

12 P. Serna, P. Concepcion and A. Corma, Design of highly active and chemoselective bimetallic gold-platinum hydrogenation catalysts through kinetic and isotopic studies, J. Catal., 2009, 265, 19-25.

13 M. Masjedi, L. T. Yildirim and S. Özkar, Novel homogeneous catalyst comprising ruthenium and trimethylphosphite for the hydrolysis of sodium borohydride, J. Mol. Catal. A: Chem., 2012, 355, 186-191.

14 M. S. Kutubi, K. Sato, K. Wada, T. Yamamoto, S. Matsumura, K. Kusada, H. Kobayashi, H. Kitagawa and K. Nagaoka, Dual Lewis Acidic/Basic $\mathrm{Pd}_{0.5} \mathrm{Ru}_{0.5}$-Poly(N-vinyl-2-pyrrolidone) Alloyed Nanoparticle: Outstanding Catalytic Activity and Selectivity in Suzuki-Miyaura Cross-Coupling Reaction, ChemCatChem, 2015, 7, 3887-3894.

15 T. E. Barder, S. D. Walker, J. R. Martinelli and S. L. Buchwald, Catalysts for Suzuki-Miyaura Coupling Processes: Scope and Studies of the Effect of Ligand Structure, J. Am. Chem. Soc., 2005, 127, 4685-4696.

16 X. F. Yang, A. Q. Wang, B. T. Qiao, J. Li, J. Y. Liu and T. Zang, Single-Atom Catalysts: A New Frontier in Heterogeneous Catalysis, Acc. Chem. Res., 2013, 46, 1740-1748.

17 R. J. Key, J. M. M. Tengco, M. D. Smith and A. K. Vannucci, A Molecular/Heterogeneous Nickel Catalyst for SuzukiMiyaura Coupling, Organometallics, 2019, 38, 2007-2014.

18 K. Fuku, T. Sakano, T. Kamegawa, K. Mori and H. Yamashita, Enhanced hydrogenation activity of nanosized Pd-Ni bimetal particles on Ti-containing mesoporous silica prepared by a photo-assisted deposition method, $J$. Mater. Chem., 2012, 22, 16243-16247.

19 S. K. Manoja, V. D'Elia, E. Pump, L. Falivene, M. Harb, S. O. Chikh, L. Cavallo and J. M. e. Basset, The Comparison between Single Atom Catalysis and Surface Organometallic Catalysis, Chem. Rev., 2020, 120, 734-813. 
20 H. Fei, J. Dong, M. J. Arellano-Jimenez, G. Ye, N. D. Kim, E. L. G. Samuel, Z. Peng, Z. Zhu, F. Qin, J. Bao, M. J. Yacaman, P. M. Ajayan, D. Chen and J. M. Tour, Atomic cobalt on nitrogen-doped graphene for hydrogen generation, Nat. Commun., 2015, 6, 8668-8671.

21 H. L. Su, S. J. Wu, Z. F. Li, Q. S. Huo, J. Q. Guan and Q. B. Kan, $\mathrm{Co}(\mathrm{II}), \mathrm{Fe}(\mathrm{III})$ or $\mathrm{VO}(\mathrm{II})$ Schiff base metal complexes immobilized on graphene oxide for styrene epoxidation, Appl. Organomet. Chem., 2015, 29, 462-467.

22 T. S. Marshall, M. O'Brien, B. Oetter, A. Corpuz, R. M. Richards, D. K. Schwartz and J. W. Medlin, Controlled selectivity for palladium catalysts using selfassembled monolayers, Nat. Mater., 2010, 9, 853-858.

23 X. S. Zhao, F. B. Su, Q. F. Yang, W. P. Guo, X. P. Bao, L. Z. Lv and C. Zhou, Templating methods for preparation of porous structures, J. Mater. Chem., 2006, 16, 637-648.

24 K. Hara, S. Tayama, H. Kano, T. Masuda, S. Takakusagi, T. Kondo, K. Uosaki and M. Sawamura, Functionalization of silicon surfaces with catalytically active Pd complexes and application to the aerobic oxidation of benzylic alcohols, Chem. Commun., 2007, 4280-4282.

25 M. L. Xiao, L. G. Feng, J. B. Zhu, C. P. Liu and W. Xing, Rapid synthesis of a PtRu nano-sponge with different surface compositions and performance evaluation for methanol electrooxidation, Nanoscale, 2015, 7, 9467-9471.

26 J. Wang, B. Mu, Z. H. Fu, L. Wang, T. S. Li and Y. J. Wu, Cyclopalladated ferrocenylimines with ester groups for Heck and Suzuki coupling reactions, Chin. J. Catal., 2014, 35(7), 1059-1067.

27 B. Mu, T. S. Li, J. Y. Li and Y. J. Wu, The highly efficient Suzuki-Miyaura cross-coupling reaction using cyclopalladated $\mathrm{N}$-alkylferrocenylimine as a catalyst in aqueous medium at room temperature under ambient atmosphere, J. Organomet. Chem., 2008, 693(7), 1243-1251.

28 B. $\mathrm{Mu}$, T. S. Li, Z. H. Fu and Y. J. Wu, Cyclopalladated ferrocenylimines catalyzed-homocoupling reaction of arylboronic acids in aqueous solvents at room temperature under ambient atmosphere, Catal. Commun., 2009, 10, 1497-1501.

29 Z. H. Fu, N. Zhang, T. S. Li, W. J. Xu and Y. J. Wu, Nhydroxymethyl acrylamide polymer brush and its application in catalyzing coupling reaction, J. Colloid Interface Sci., 2013, 394, 409-418.

30 N. Zhao, T. S. Li, Z. Zhai, J. J. Qiu, W. J. Xu, M. H. Liu and Y. J. Wu, Cyclopalladated Arylimine Self-Assembly Films for Suzuki Reaction, ChemCatChem, 2013, 5(6), 1481-1489.

31 Z. H. Fu, T. S. Li, X. H. He, J. Liu, W. J. Xu and Y. J. Wu, Cyclopalladated ferrocenylimine functionalized polymer brushes film and its mechanism investigation of heterogeneous catalysis, J. Mol. Catal. A: Chem., 2014, 395, 293-299.

32 H. Liu, T. S. Li, X. X. Xue, W. J. Xu and Y. J. Wu, The mechanism of a self-assembled Pd (ferrocenylimine)-Si compound-catalysed Suzuki coupling reaction, Catal. Sci. Technol., 2016, 6, 1667-1676.

33 Z. Q. Xue, P. P. Huang, T. S. Li, P. X. Qin, D. Xiao, M. H. Liu, P. L. Chen and Y. J. Wu, A novel "tunnel-like" cyclopalladated arylimine catalyst immobilized on grapheme oxide nano-sheet, Nanoscale, 2017, 9, 781-791.

34 X. Gu, T. S. Li, P. L. Chen, M. H. Liu and Y. J. Wu, A Facile Fabrication of Ordered Component-tunable Heterobimetallic Self-assembly Nano-sheet for Catalyzing Click Reaction, ACS Omega, 2107, 2, 5415-5433.

35 L. H. Wang, P. P. Huang, J. Yang, T. S. Li, L. Y. Mao, M. H. Liu and Y. J. Wu, Fabrication and Catalytic Properties of Ordered Cyclopalladated Diimine Monolayer-Investigation on Catalyzing Mechanism, RSC Adv., 2018, 8, 31860-31867.

36 P. P. Huang, Z. Q. Xue, T. S. Li, Z. Y. Liu, D. H. Wei, M. H. Liu and Y. J. Wu, Investigation on Electron Distribution and Synergetic to Enhance Catalytic Activity in Bimetallic Ni(II)/ Pd(II) Molecular Monolayer, ChemCatChem, 2018, 10, 5141-5155.

37 P. P. Huang, E. R. Song, Y. M. Sun, T. S. Li, M. H. Liu and Y. J. Wu, Schiff-based Pd(II)/Fe(III) Bimetallic Self-assembly Monolayer-Preparation, Structure, Catalytic Dynamic and Synergistic, Mol. Catal., 2019, 469, 75-86.

38 W. L. Shang, X. F. Zeng, T. S. Li, W. J. Xu, D. H. Wei, M. H. Liu and Y. J. Wu, Controlled Distribution of Active Centre to Enhance Catalytic Activity of Ordered Pd/Co Catalytic Nano-monolayer, J. Catal., 2019, 376, 228-237.

39 E. R. Song, J. Wang, T. S. Li, W. D. Zhao, M. H. Liu and Y. J. Wu, Novel Ordered Cyclopalladated Aryl Imine Monolayers-Structure Designing for Enhancing Catalytic Performance, Mol. Catal., 2020, 482, 110671.

40 A. A. Ensafi, M. Jafari-Asl and B. Rezaei, Graphene nanosheets functionalized with 4-aminothiophenol as a stable support for the oxidation of formic acid based on self-supported Pd-nanoclusters via galvanic replacement from $\mathrm{Cu}_{2} \mathrm{O}$ nanocubes, J. Electroanal. Chem., 2014, 731, 20.

41 W. Yuan and G. Shi, Graphene-based gas sensors, J. Mater. Chem. A, 2013, 1, 10078-10091.

42 J. Li, Q.-L. Zhu and Q. Xu, Non-noble bimetallic CuCo nanoparticles encapsulated in the pores of metal-organic frameworks: synergetic catalysis in the hydrolysis of ammonia borane for hydrogen generation, Catal. Sci. Technol., 2015, 5, 525-530.

43 H. L. Jiang, T. Akita, T. Ishida, M. Haruta and Q. Xu, Synergistic Catalysis of Au@Ag Core-Shell Nanoparticles Stabilized on Metal-Organic Framework, J. Am. Chem. Soc., 2011, 133, 1304-1306.

44 S. Maheswari, S. Karthikeyan, P. Murugan, P. Sridhar and S. Pitchumani, Carbon-Supported $\mathrm{Pd}-\mathrm{Co}$ as Cathode Catalyst for Apemfes and Validation by DFT, Phys. Chem. Chem. Phys., 2012, 14, 9683-9695.

45 S. Z. Tasker, E. A. Standley and T. F. Jamison, Recent advances in homogeneous nickel catalysis, Nature, 2014, 509(7500), 299-309.

46 J. Yamaguchi, K. Muto and K. Itami, Recent Progress in Nickel-Catalyzed Biaryl Coupling, Eur. J. Org. Chem., 2013, 19-30.

47 B. M. Rosen, K. W. Quasdorf, D. A. Wilson, N. Zhang, A. M. Resmerita, N. K. Garg and V. Percec, NickelCatalyzed Cross-Couplings Involving Carbon-Oxygen Bonds, Chem. Rev., 2011, 111, 1346-1416. 
48 S. Singh and R. B. Sunoj, Mechanism and Origin of Enantioselectivity in Nickel-Catalyzed Alkyl-Alkyl Suzuki Coupling Reaction, J. Phys. Chem. A, 2019, 123, 6701-6710.

49 F. S. Han, Transition-metal-catalyzed Suzuki-Miyaura crosscoupling reactions: a remarkable advance from palladium to nickel catalysts, Chem. Soc. Rev., 2013, 42, 5270-5298.

50 R. Q. Li, H. Xu, N. Zhao, X. J. Jin and Y. F. Dang, Origins of Chemoselectivity in the Ni-Catalyzed Biaryl and PdCatalyzed Acyl Suzuki-Miyaura Cross-Coupling of N-Acetyl-Amides, $J$. Org. Chem., 2020, 85, 833-840.

51 C. S. Zhang, R. H. Zhao, W. M. Dagnaw, Z. Y. Liu, Y. Lu and Z. X. Wang, Density Functional Theory Mechanistic Insight into the Base-Free Nickel-Catalyzed Suzuki-Miyaura CrossCoupling of Acid Fluoride: Concerted versus Stepwise Transmetalation, J. Org. Chem., 2019, 84, 13983-13991.

52 P. A. Payard, L. A. Perego, I. Ciofini and L. Grimaud, Taming Nickel-Catalyzed Suzuki-Miyaura Coupling: A Mechanistic Focus on Boron-to-Nickel Transmetalation, ACS Catal., 2018, 8, 4812-4823.

53 Z. C. Cao, S. J. Xie, H. Y. Fang and Z. J. Shi, Ni-Catalyzed Cross-Coupling of Dimethyl Aryl Amines with Arylboronic Esters under Reductive Conditions, J. Am. Chem. Soc., 2018, 140, 13575-13579.

54 S. Akkarasamiyo, J. Margalef and J. S. M. Samec, NickelCatalyzed Suzuki-Miyaura Cross-Coupling Reaction of Naphthyl and Quinolyl Alcohols with Boronic Acids, Org. Lett., 2019, 21, 4782-4787.

55 R. J. Key, J. M. M. Tengco, M. D. Smith and A. K. Vannucci, A Molecular/Heterogeneous Nickel Catalyst for SuzukiMiyaura Coupling, Organometallics, 2019, 38(9), 2007-2014.

56 S. B. Tailor, M. Manzotti, S. Asghar, B. J. S. Rowsell, S. L. J. Luckham, H. A. Sparkes and R. B. Bedford, Revisiting Claims of the Iron-, Cobalt-, Nickel-, and Copper-Catalyzed Suzuki Biaryl Cross-Coupling of Aryl Halides with Aryl Boronic Acids, Organometallics, 2019, 38(8), 1770-1777.

57 A. M. Oertel, V. Ritleng and M. J. Chetcuti, Synthesis and Catalytic Activity in Suzuki Coupling of Nickel Complexes Bearing n-Butyl- and Triethoxysilylpropyl-Substituted NHC Ligands: Toward the Heterogenization of Molecular Catalysts, Organometallics, 2012, 31, 2829-2840.

58 A. K. Cooper, D. K. Leonard, S. Bajo, P. M. Burton and D. J. Nelson, Aldehydes and ketones influence reactivity and selectivity in nickel-catalysed Suzuki-Miyaura reactions, Chem. Sci., 2020, 11, 1905-1911.

59 X. Y. Lu, L. Y. Yan, J. S. Li, J. M. Li, H. P. Zhou, R. C. Jiang, C. C. Liu, R. Lu and R. Hu, Base-free Ni-catalyzed Suzukitype cross-coupling reactions of epoxides with boronic acids, Chem. Commun., 2020, 56, 109-112.

60 Y. Dong, J. J. Jv, Y. Li, W. H. Li, Y. Q. Chen, Q. Sun, J. P. Ma and Y. B. Dong, Nickel-metalated porous organic polymer for Suzuki-Miyaura cross-coupling reaction, RSC Adv., 2019, 9, 20266-20272.

61 S. D. Ramgren, L. Hie, Y. Ye and N. K. Garg, Nickel-Catalyzed Suzuki-Miyaura Couplings in Green Solvents, Org. Lett., 2013, 15, 3950-3953.
62 J. Xia, Y. Fu, G. He, X. Q. Sun and X. Wang, Core-shell-like NiPd nanoparticles supported on carbon black as a magnetically separable catalyst for green Suzuki-Miyaura coupling reactions, Appl. Catal., B, 2017, 200, 39-46.

63 S. Jang, T. Kim and K. H. Park, Fabrication of Crumpled BallLike Nickel Doped Palladium-Iron Oxide Hybrid Nanoparticles with Controlled Morphology as Effective Catalyst for Suzuki-Miyaura Coupling Reaction, Catalysts, 2017, 7(9), 247.

64 A. Ohtaka, J. M. Sansano, C. Nájera, et al., Palladium and Bimetallic Palladium-Nickel Nanoparticles Supported on Multiwall Carbon Nanotubes: Application to CarbonCarbon Bond-Forming Reactions in Water, ChemCatChem, 2015, 7(12), 1841-1847.

65 M. Sera, M. Yamashita, Y. Ono, T. Tabata, E. Muto, T. Ouchi and H. Tawada, Development of Large-Scale Synthesis using a Palladium-Catalyzed Cross-Coupling Reaction for an Isoquinolone Derivative as a Potent DPP-4 Inhibitor, Org. Process Res. Dev., 2014, 18, 446-453.

66 Y. E. Wu, D. S. Wang, P. Zhao, Z. Q. Niu, Q. Peng and Y. D. Li, Monodispersed Pd-Ni nanoparticles: composition control synthesis and catalytic properties in the Miyaura-Suzuki reaction, Inorg. Chem., 2011, 50, 2046-2048.

67 G. Y. Bao, J. Bai and C. P. Li, Synergistic effect of the Pd-Ni bimetal/carbon nanofiber composite catalyst in Suzuki coupling reaction, Org. Chem. Front., 2019, 6, 352-361.

68 E. D. Sultanova, A. I. Samigullina, N. V. Nastapova, I. R. Nizameev, K. V. Kholin, V. I. Morozov, A. T. Gubaidullin, V. V. Yanilkin, M. K. Kadirov, A. Y. Ziganshina and A. I. Konovalov, Highly active Pd-Ni nanocatalysts supported on multicharged polymer matrix, Catal. Sci. Technol., 2017, 7, 5914-5919.

69 R. K. Rai, K. Gupta, D. Tyagi, A. Mahata, S. Behrens, X. Yang, Q. Xu, B. Pathakad and S. K. Singh, Access to highly active Ni-Pd bimetallic nanoparticle catalysts for C-C coupling reactions, Catal. Sci. Technol., 2016, 6(14), 5567-5579.

70 H. Su, Z. Li, Q. Huo, J. Guan and Q. Kan, Immobilization of transition metal $\left(\mathrm{Fe}^{2+}, \mathrm{Co}^{2+}, \mathrm{VO}^{2+}\right.$ or $\left.\mathrm{Cu}^{2+}\right)$ Schiff base complexes onto graphene oxide as efficient and recyclable catalysts for epoxidation of styrene, $R S C A d v ., 2014,4$, 9990-9997.

71 H. P. Mungse, S. Verma, N. Kumar, B. Sain and O. P. Khatri, Grafting of oxo-vanadium Schiff base on graphene nanosheets and its catalytic activity for the oxidation of alcohols, J. Mater. Chem., 2012, 22, 5427-5433.

72 Z.-G. Le, Z. Liu, Y. Qian and C. Wang, A facile and efficient approach to decoration of graphene nanosheets with gold nanoparticles Appl, Surf. Sci., 2012, 258, 5348-5353.

73 Z. Li, S. Wu, H. Ding, D. Zheng, J. Hu, X. Wang, Q. Huo, J. Guan and Q. Kan, Immobilized $\mathrm{Cu}(\mathrm{ii})$ and $\mathrm{Co}(\mathrm{ii})$ salen complexes on graphene oxide and their catalytic activity for aerobic epoxidation of styrene, New J. Chem., 2013, 37, 1561-1568.

74 S. Choudhary, H. P. Mungse and O. P. Khatri, Dispersion of alkylated graphene in organic solvents and its potential for lubrication applications, J. Mater. Chem., 2012, 22, 21032. 
75 Y. Zu, J. Tang, W. Zhu, M. Zhang, G. Liu, Y. Liu, W. Zhang and M. Jia, Graphite oxide-supported $\mathrm{CaO}$ catalysts for transesterification of soybean oil with methanol, Bioresour. Technol., 2011, 102, 8939-8944.

76 T. Nakamoto and T. Moriizumi, A Theory of a Quartz Crystal Microbalance Based upon a Mason Equivalent Circuit, Jpn. J. Appl. Phys., 1990, 29, 963-969.

77 K. Takada, G. D. Storrier, F. Pariente and H. D. Abrunã, EQCM Studies of the Redox Processes during and after Electropolymerization of Films of Transition-Metal Complexes of Vinylterpyridine, J. Phys. Chem. B, 1998, 102, 1387-1396.

$78 \mathrm{~W}$. A. Herrmann and B. Cornils, Organometallic Homogeneous Catalysis-Quo vadis?, Angew. Chem., Int. Ed., 1997, 36, 1048-1067.

79 Ö. Metin, S. F. Ho, C. Alp, H. Can, M. N. Mankin, M. S. Gültekin, M. Chi and S. Sun, Ni/Pd Core/Shell Nanoparticles Supported on Graphene as a Highly Active and Reusable Catalyst for Suzuki-Miyaura Cross-Coupling Reaction, Nano Res., 2013, 1, 10-18.

80 H. Göksu, H. Can, K. Sendil, M. S. Gültekin and Ö. Metin, Reduced Graphene Oxide Supported CoPd Nanoalloys Catalyzed Tandem Ammonia Borane Dehydrogenationand Hydrogenation of Aromatic Nitro, Nitrile and Carbonyl Compounds, Appl. Catal., A, 2014, 488, 176-182.

81 B. C. Gates, Supported Metal Clusters: Synthesis, Structure, and Catalysis, Chem. Rev., 1995, 95, 511-522.

82 C. H. Bartholomew, Mechanisms of catalyst deactivation, Appl. Catal., A, 2001, 212, 17-60.

83 S. Özkar, R. G. Finke, S. Özkar and R. G. Finke, Nanocluster Formation and Stabilization Fundamental Studies: Ranking Commonly Employed Anionic Stabilizers via the Development, Then Application, of Five Comparative Criteria, J. Am. Chem. Soc., 2002, 124, 5796-5810.

84 M. L. H. Green, A New Approach to the Formal Classification of Covalent Compounds of the Elements, J. Organomet. Chem., 1995, 500, 127-148.
85 A. J. Medford, A. Vojvodic, J. S. Hummelshøj, J. Voss, F. A. Pedersen, F. Studt, T. Bligaard, A. Nilsson and J. K. Nørskov, From the Sabatier principle to a predictive theory of transition-metal heterogeneous catalysis, $J$. Catal., 2015, 328, 36-42.

86 V. Ponec, Alloy catalysts: the concepts, Appl. Catal., A, 2001, 222, 31-45.

87 A. Christensen, A. V. Ruban, P. Stoltze, K. W. Jacobsen, H. L. Shriver and J. Nørskov, Phase diagrams for surface alloys, Phys. Rev. B: Condens. Matter Mater. Phys., 1997, 56, 5822-5834.

88 P. V. Helden, F. Prinsloo, J.-A. van den Berg, B. Xaba, W. Erasmus, M. Claeys and Jan van de Loosdrecht, Cobaltnickel bimetallic Fischer-Tropsch catalysts: a combined theoretical and experimental approach, Catal. Today, 2020, 342, 88-98.

89 X. P. Zhang, J. X. Wang, B. J. Tan, N. Zhang, J. J. Bao and G. H. He, Ce-Co interaction effects on the catalytic performance of uniform mesoporous $\mathrm{Ce}_{\mathrm{x}}-\mathrm{Co}_{\mathrm{y}}$ catalysts in $\mathrm{Hg}^{0}$ oxidation process, Fuel, 2018, 226, 18-26.

90 D. H. Wei, X. Q. Huang, Y. Qiao, J. L. Wang, L. Fei and C. G. Zhan, Catalytic Mechanisms for Cofactor-Free Oxidase-Catalyzed Reactions: Reaction Pathways of Uricase-Catalyzed Oxidation and Hydration of Uric Acid, ACS Catal., 2017, 4623-4636.

91 Y. Wang, D. H. Wei and M. S. Tang, Computational Study on $\gamma$-C-H Functionalization of $\alpha, \beta$-Unsaturated Ester Catalyzed by N-Heterocyclic Carbene: Mechanisms, Origin of Stereoselectivity, and Role of Catalyst, J. Org. Chem., 2017, 82, 13043-13050.

92 N. Liu, Y. F. Xie, C. Wang, S. J. Li, D. H. Wei and B. Dai, Cooperative Multifunctional Organocatalysts for Ambient Conversion of Carbon Dioxide into Cyclic Carbonates, ACS Catal., 2018, 8, 9945-9957.

93 G. Voss, J. Fløystad, A. Voronov and M. Rønning, The State of Nickel as Promotor in Cobalt Fischer-Tropsch Synthesis Catalysts, Top. Catal., 2015, 58, 896-904. 